International Journal of Advanced Academic Research (Sciences, Technology and Engineering) | ISSN: 2488-9849

Journal DOI: 10.46654/ij.24889849

Vol. 6, Issue 10 (October, 2020) | www.ijaar.org

Article DOI: 10.46654/ij.24889849.e6102

\title{
PROPERTY ENHANCEMENT AND OPTIMIZATION OF POLYPROPYLENE MATRIX FOR AUTOMOBILE APPLICATION: INFLUENCE OF COIR FIBER PROPORTION AND LENGTH
}

\author{
Akinwande Abayomi Adewale, Barnabas Abel Adeiza, Balogun Oluwatosin Abiodun, \\ Daniel P. T. and Shittu S. A. \\ Department of Metallurgical and Materials Engineering, Federal University of Technology, \\ Akure, Ondo State, Nigeria. \\ *Corresponding author email: abypublications@ gmail.com
}

\begin{abstract}
Coir-polypropylene composite was developed by the addition of coir fiber treated with $1.7 \mathrm{M}$ $\mathrm{NaOH}$ solution for 24 hours at fiber loading $0-30 \mathrm{wt}$. \% for automobile application. The fibers were cut to different length of $20-50 \mathrm{~mm}$. Samples produced were subjected to test to examine tensile and flexural strengths and moduli, impact strength and hardness. Microstructural analysis was also carried out. Results obtained reveal rise in tensile strength with increasing fiber proportion up to $15 \mathrm{wt}$. \% before a decline down to $30 \mathrm{wt}$. \%. Increasing fiber length was observed to contribute to appreciation in strength up to $40 \mathrm{~mm}$. Tensile modulus (TM) trended upward with in increased fiber loading up to $30 \mathrm{wt}$. \% for length from 20 to $40 \mathrm{~mm}$ and for fiber cut to $50 \mathrm{~mm}$, TM appreciated up to $15 \mathrm{wt}$. \% before eventual depreciation. Results of flexural strength and modulus showed that flexural strength rose with increasing fiber loading up to 30 wt. \% for coir fibers cut to 20 to $40 \mathrm{~mm}$. Coir cut to $50 \mathrm{~mm}$, gave increase up to $15 \mathrm{wt}$. \% before eventual decrease in value. Flexural modulus rose from 0 to $30 \mathrm{wt}$. \% for all fiber length except when $50 \mathrm{~mm}$ length was incorporated into the composite resulting lower modulus when compared with the ones recorded for coir of $40 \mathrm{~mm}$ length.
\end{abstract}

Keywords: Automobile, Coir fiber, fiber proportion, fiber length, optimization. 


\section{INTRODUCTION}

Automobile is a complex vehicle propelled by internal combustion engine designed to convey passengers or goods from one location to another and it's made of many parts[1]. Some parts are made of metals and their composites, some ceramics and their composites while others are made of polymers and their composites. For fuel efficiency, emphases are made on light materials to be incorporated into vehicles. Of these classes of materials aforementioned, polymer and its composites are the lightest and as such they have drawn attentions of automobile makers. Utilization of these polymers in vehicles has made cars lighter when compared with ones made in the 60s and 70s. Polymeric materials employed in automobile parts are ABS, polyvinyl chloride, polycarbonate and polypropylene. These polymeric materials were chosen based on their engineering properties.

Of these highlighted polymers, the cheapest is polypropylene. Therefore, utilization of polypropylene (PP)in applications where ABS and polycarbonates are used in automobile could be encouraged especially when properties of PP are enhanced despite its limitation.

Improvement on properties of PP can enhance its usage in engineering applications; in this case automobile. In achieving improvement in properties, additives are introduced which could be particulates[2-4] or fibers[5-10] or combination of both [11, 12]. Natural fibers have been engaged by different researchers in enhancing properties of polymer [13, 14] of which polypropylene is not excluded. These fibers are sisal, banana fiber, bamboo fiber, oil palm fruit fiber, kenaf fibers to mention but a few. Selection and utilization of these natural fibers are based on different mechanical properties exhibited. Since natural fibers are cheap, incorporating them into polymer may not necessarily increase the price of polymer composites beyond affordability when compared to the synthetic ones $[15,16]$. These fibers have produced different changes in the matrix and properties of the parent materials[17, 18].Particulates or powders are another form of additives which when integrated in polymer provoke different properties in the finished composite. Particulate/powders serve as fillers [19]in the matrix and can be nano fillers[20], biofillers[21, 22] or synthetic fillers [23-25]. In some studies, both fibers and particulate are blended into polymer matrix producing hybrid composites [26-28] of different grades. Consequently, hybrid composites made of the mix of two fibers are common practice in materials development [29-32].

Previous works carried out engaged fibers in polymer matrix produced different results in mechanical and physical properties. Utilization of bamboo fiber in polymer has provided different results in polymer matrix. Bamboo treated in $\mathrm{NaOH}$ for 12 hours was incorporated in epoxy composites [33] at different fiber length. Observation made was that at fiber length proportion of 10-30 wt. \%, flexural modulus improved. Equally, the same property was enhanced with increasing fiber length. From the study, it could be noticed that incorporation of $\mathrm{NaOH}$ treated fiber cut to increasing length of 5, 10 and $15 \mathrm{~mm}$ enhanced flexural properties of the fiber. Treatment of fiber, results in removal of wax on fiber surface which eventually promote interfacial adhesion enhancing mechanical and physical properties. Addition of bamboo fiber up to $50 \%$ was noted to give proportional enhancement in PP properties, however, at $60 \%$, there 
was lowering of the values which can be affixed to possible fiber pull out[34].Another very useful fiber for reinforcement is banana and jute fiber. [35] used banana fiber, jute fiber and combination of the two in epoxy resin. It was observed that longitudinal tensile strength trended upward from $10-30 \mathrm{wt}$ \% fiber loading. Jute fiber presented higher longitudinal tensile strength than banana fiber even as combined fiber gave the highest enhancement. [35] linked the fact that lowest value of transverse tensile strength to lower reinforcement-matrix bonding or possible incomplete adhesion of the fiber with matrix. Highest value of property was recorded on incorporation of jute-fiber combination and this was linked to decrease in porosity. Transverse tensile strength peaked at $20 \mathrm{wt}$. \% of the fibers with highest value occurring on addition of the fiber combinations and trended downwards at $30-40 \mathrm{wt}$. \% fiber loading depicting a quadratic regression model. Transverse flexural strength peaked at $10 \%$ loading with fall in value from 20 wt. \% while the longitudinal tensile strength attained its maximum at 30 wt. \% fiber loading. Improvement of up to $126 \%$ were recorded in this study for banana/jute fiber combination based on higher compatibility, as well as dispersion in hybrid composites amounting to even stress distribution within composite. Owing to availability and the cheaper cost of coir fiber, the fiber was utilized in the study with respect to varying proportion and fiber length as carried out in epoxy [36], polyester [37], high density polyethylene [38] and polypropylene [39].Coir fiber and coconut shell powder were utilized in enhancing properties of PP matrix for automobile application putting into consideration the fact that polypropylene is cheaper than commonly used plastics used in automobile (ABS, PC, PVS) and coir fiber and coconut shell powder are cheaper since they are agro waste materials.

\section{MATERIALS AND METHODS}

Materials used in the study are polypropylene, coir fiber obtained from coconut shell, coconut shell powder which was gotten by milling of the shell and sieving to $-75 \mu \mathrm{m}$, sodium hydroxide $(\mathrm{NaOH})$ and distilled water. The coir fibers were washed using distilled water and air dried for 3 days after which they were treated in $1.7 \mathrm{M} \mathrm{NaOH}$ aqueous solution for 24 hours. Afterwards the fibers were rinsed with distilled water and air dried for another 5 days. Sequel to this was the cutting of the fiber into lengths of 10,20,30 and $40 \mathrm{~mm}$. Polypropylene composite samples were produced by the blending of coir (cut to the length of 20,30, 40 and $50 \mathrm{~mm}$ )at varied proportion of0, 5, 10, 15, 20, 25 and $30 \mathrm{wt}$ \% of polypropylene with coconut shell powder (10 wt. \%). Compounding was done in even distribution of the fiber and compression moulding machine was used in moulding into samples for different tests. Tests were carried out for tensile and flexural properties, hardness and impact strengths in line with [40-43] [ASTM D3039M-17] [ASTM D790-17] [ASTM D256-10] [ASTM D785-08] respectively. Tensile test was carried out using dumb bell shaped samples of dimension $90 \mathrm{~mm} \times 10 \mathrm{~mm} \times 5 \mathrm{~mm}$ employing a universal testing machine (WDW-100). Applied load of $100 \mathrm{~N}$ was applied at $5 \mathrm{~mm} / \mathrm{min}$. Average value of the three test samples representing each mix was obtained and further evaluation was carried out in determining tensile strength and tensile modulus. Flexural test was carried out on samples of 120 $\mathrm{mm}$ length, width of $15 \mathrm{~mm}$ with thickness of $3 \mathrm{~mm}$ under 3 points bending tests using the same testing machine and loading rate of $10 \mathrm{~mm} / \mathrm{min}$. Izod impact test was done on samples $64 \mathrm{~mm}$ long and $11 \mathrm{~mm}$ having thickness of $3 \mathrm{~mm}$ and notched at the center. Hounsfield balanced impact testing machine (serial number 3915-h10-5) was employed and values after fracture were 
recorded. Rockwell hardness was done on samples $6 \mathrm{~mm}$ thick using a ball indenter of diameter $1.588 \mathrm{~mm}$ and applied force of $100 \mathrm{~N}$ in line with [43] [ASTM D 785].

\section{RESULTS AND DISCUSSION}

\subsection{Tensile strength (TS) and tensile modulus (TM)}

\section{a. Analysis of experimental results}

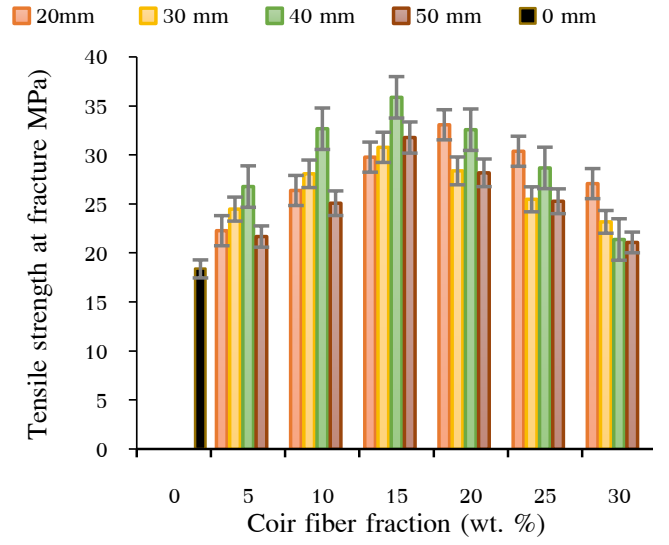

(a)

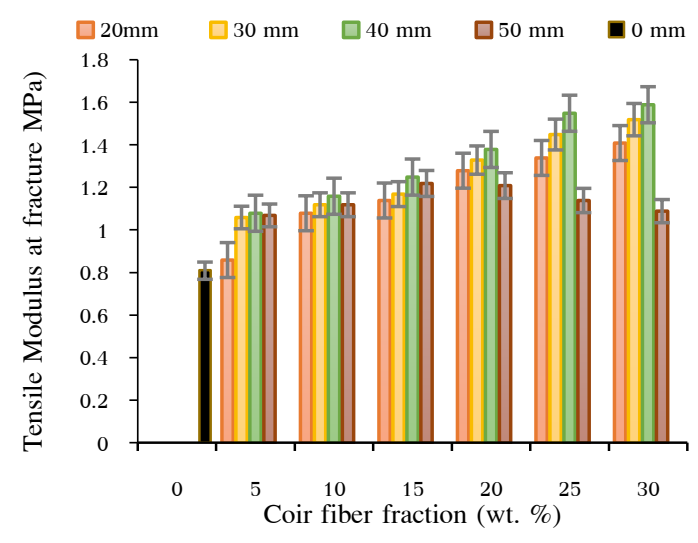

(b)

Fig. 1(a): Influence of coir weight fraction $(0,5,10,15,20,25$ and 30 wt. \%) and fiber length $(20,30,40,50$ and $60 \mathrm{~mm})$ on (a) tensile strength (b) tensile modulus.

Influence of fiber proportion and fiber length on tensile strength revealed (Fig. 1) was noted to appreciate in value from $0-20 \mathrm{wt}$. \% fiber for $20 \mathrm{~mm}$ fiber length, after which there was fall in value. For 30-50 mm length of fiber, TS rose from 0 and peaked at $15 \mathrm{wt}$. \% fiber after which there was depreciation in the values. The increase in the strength with fiber weight fraction can be associated with enhanced interfacial adhesion with the matrix at that weight fraction. Alkaline modification exposes the roughness of the fiber surface thereby improving fiber matrix adhesion[44].Reduction in TS was experienced attributable to fiber clog/intertwine and complex fiber network formed within matrix which further inhibits the stretching of the samples. Results obtained in Fig. 1 as per performance at respective fiber fraction corroborates the observations of $[45,46,47,48]$ in which values of TS peaked at 15-20 wt. \% fiber. TS rose with increasing fiber length up to $40 \mathrm{~mm}$ (Fig 1) after which there was consistent reduction up to $50 \mathrm{~mm}$ implying coir fiber length up to $40 \mathrm{~mm}$ is adequate in increasing tensile strength. With fiber presence $>40 \%$, there is higher tendency of fiber interlocking amounting into reduced flexibility of fiber.

TS was found to improve with increasing coir fiber length up to $40 \mathrm{~mm}$ after which there was reduction. Higher fiber length improves interfacial bonding and flexibility. Reduction in the strength when introducing $50 \mathrm{~mm}$ coir fiber may be connected to possible fiber interlocking. For optimum value of TS coir fiber length $\leq 40 \mathrm{~mm}$ is recommended. 
Values obtained in this study ranged from 18.4 to $35.9 \mathrm{MPa}$ with 39.5 being the highest TS when 15 wt. \% coir fiber of length $40 \mathrm{~mm}$ was incorporated into polypropylene matrix which is higher than the value obtained in previous study $[45,47]$ where $1-3 \mathrm{~mm}$ fiber length was used. The discrepancy is traced to fiber length utilized in that the fiber is longer in this study as compared to length of fiber employed in that study[47].

Tensile modulus (TM) as indicated in Fig. 1(b) trends upward with increment in fiber weight fraction. This ensued based on increased toughness as a result of fiber inclusion. Presence of fiber within matrix serve as obstacle to the free movement of dislocation [49] and this improves strain hardening with consequent increase in strain, effectuating higher stiffness. As per tensile modulus, result obtained tallies with observations of $[46,50,51]$. TM was noted to increase from 0-25\% in the study. With respect to the fiber length, the modulus appreciated in value from 20 $\mathrm{mm}$ to $40 \mathrm{~mm}$. A contrast behaviour was exhibited when $50 \mathrm{~mm}$ fiber length was added, in that tensile modulus reduced. Also, when considering weight fraction of coir fibers cut to $50 \mathrm{~mm}$, TM trended upward between 0 and $20 \mathrm{wt}$. $\%$ and at 25 and $30 \mathrm{wt}$. \% there was reduction. Therefore maximum value was attained for TM fiber length when $30 \%$ of treated coir fiber cut to $30 \mathrm{~mm}$ was incorporated into polypropylene matrix. In [52], TM increased with coir fiber length from 0 to $35 \mathrm{~mm}$. This observation agrees with the result obtained in this study affirming the reinforcement ability of coir fiber.

\section{b. Regression model of Tensile strength and tensile modulus of coir-polypropylene of varying lengths}

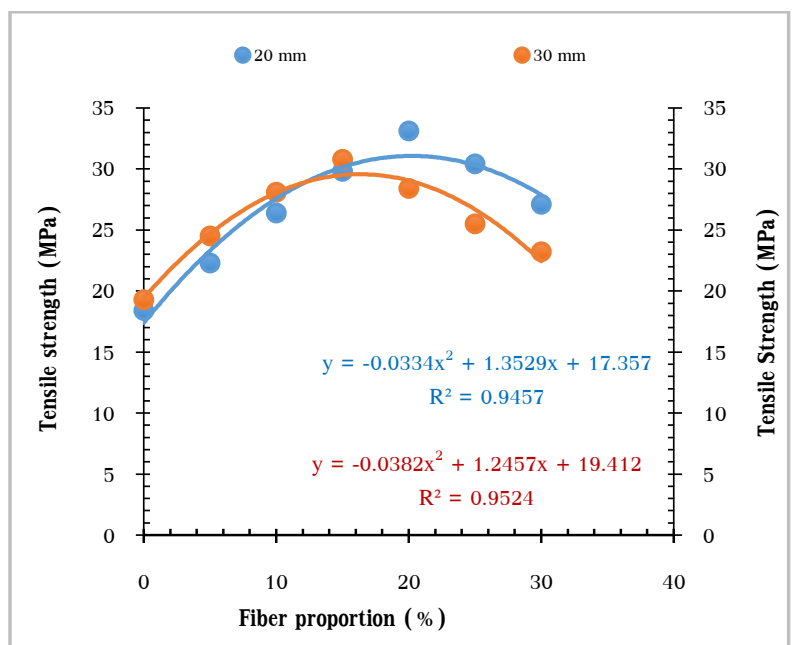

(a)

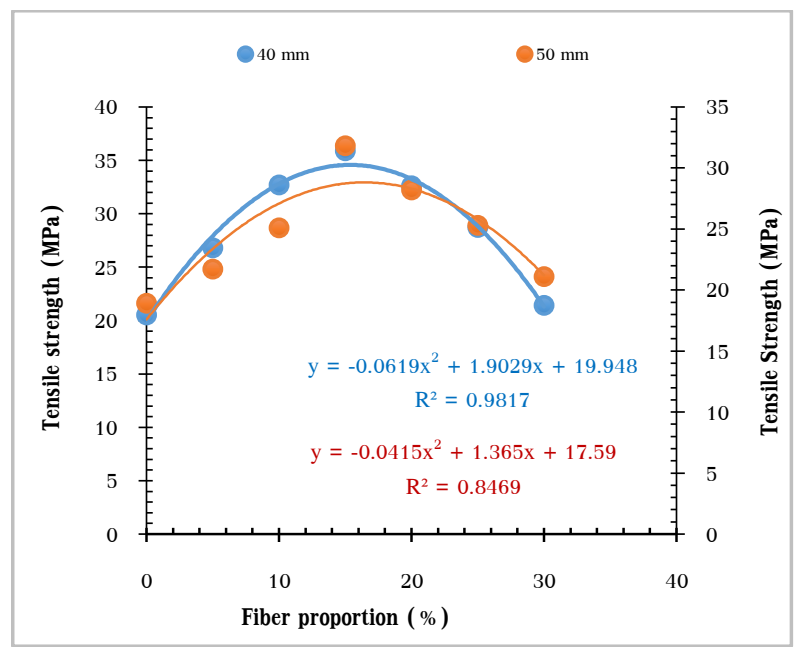

(b)

Fig. 2: Regression model for Tensile strength at varied coir fiber proportion and lengths of (a) 20 and $30 \mathrm{~mm}$ (b) 40 and $50 \mathrm{~mm}$

Fig. 2 presents regression model reflecting relationship between tensile strength and coir fiber weight percent with models depicting quadratic equations for the 4 models. Coefficients of determination $\mathrm{R}^{2}$ are $0.9457,0.9524,0.9817$ and 0.8469 for fiber length 20, 30, 40 and $50 \mathrm{~mm}$ length. From the value of the $\mathrm{R}^{2}$, deduction made is that as fiber length increased, there is higher 
correlation between tensile strength and weight fraction of the fiber which climaxed when fiber length was $40 \mathrm{~mm}$.

\section{c. Regression model of tensile modulus of coir-polypropylene of varying lengths}

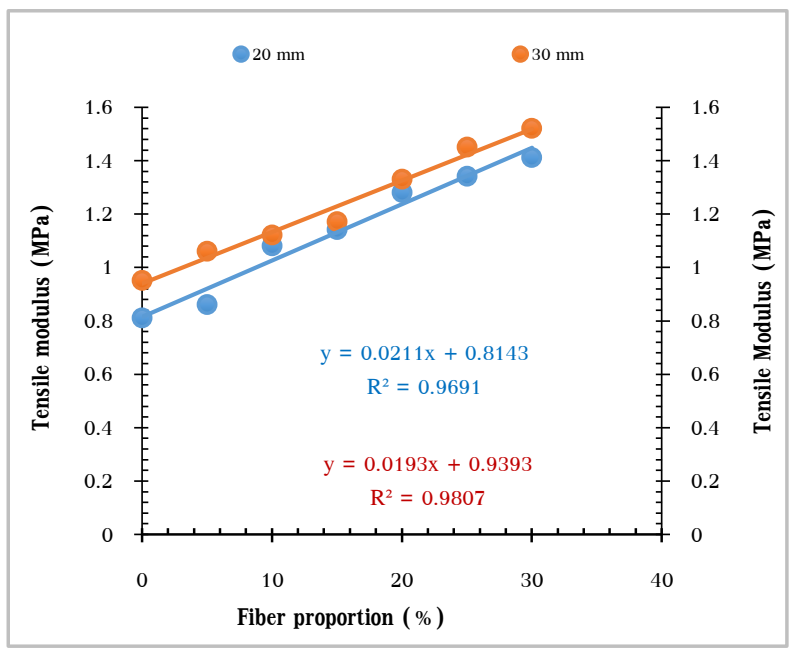

(a)

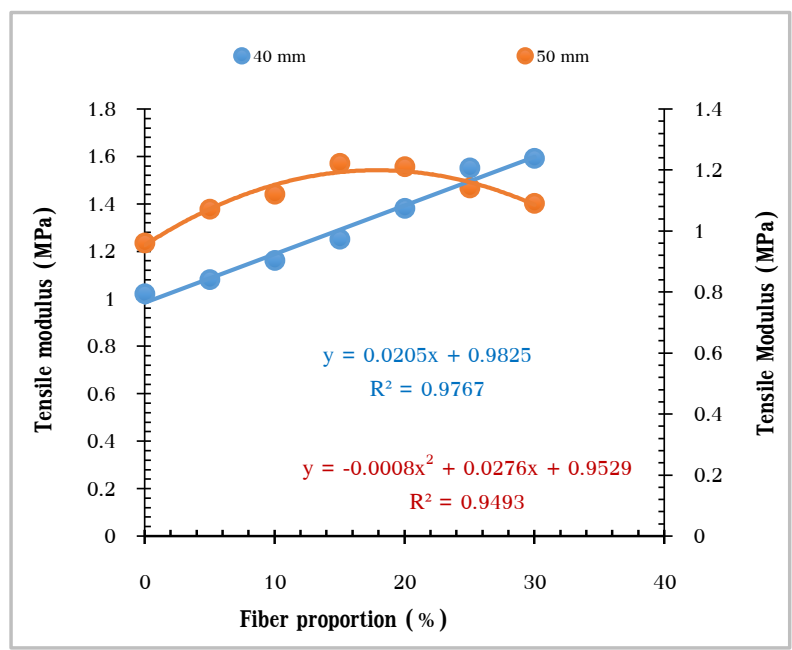

(b)

Fig. 3: Regression model for tensile modulus at varied coir fiber proportion and lengths of (a) 20 and $30 \mathrm{~mm}$ (b) 40 and $50 \mathrm{~mm}$

Fig. 3 highlights linear regression model reflecting the relationship between tensile modulus (TM) and coir fiber weight percent at $20 \mathrm{~mm}$ to $50 \mathrm{~mm}$ length. Coefficients of determination $\mathrm{R}^{2}$ are $0.9691,0.9807,0.9767$ and 0.8469 for fiber length 20, 30, 40 and $50 \mathrm{~mm}$ length. From the value of the $\mathrm{R}^{2}$, deduction made is that as fiber length increased from 20 to $30 \mathrm{~mm}$, there is higher correlation between tensile modulus and fiber proportion. With increasing fiber loading (coir fiber $40 \mathrm{~mm}$ ), the value was lower, however the model still shows $98 \%$ correlation. In the case of coir fiber of $40 \mathrm{~mm}$, the relationship is linear as depicted in Fig. 3bwith $97 \%$ correlation. Correlation for tensile modulus vs fiber weight fraction for coir fiber cut to $50 \mathrm{~mm}$ is quadratic (best line of fit) with $\mathrm{R}^{2}$ of 0.9403 . 


\section{d. 2D contour and 3D response surface plot for tensile strength}

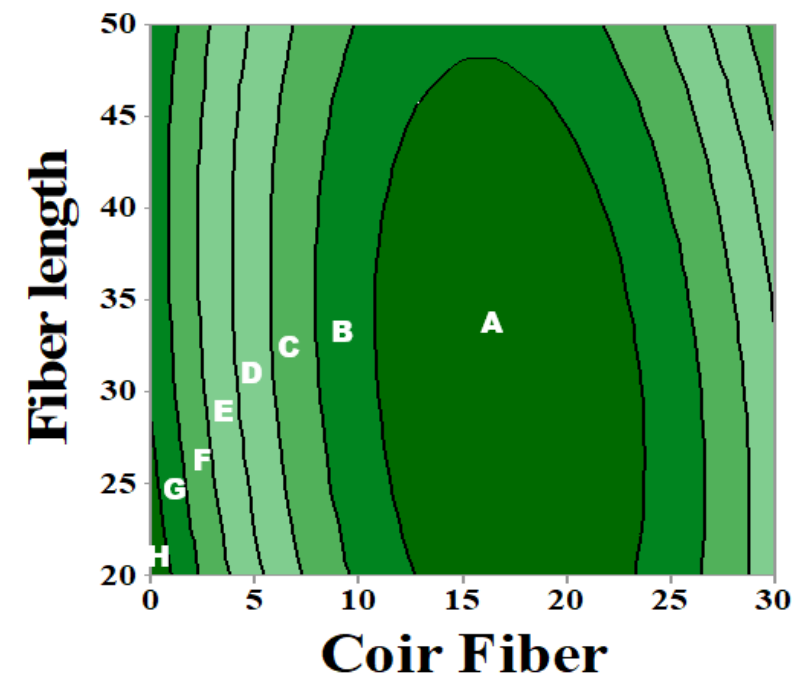

(a)

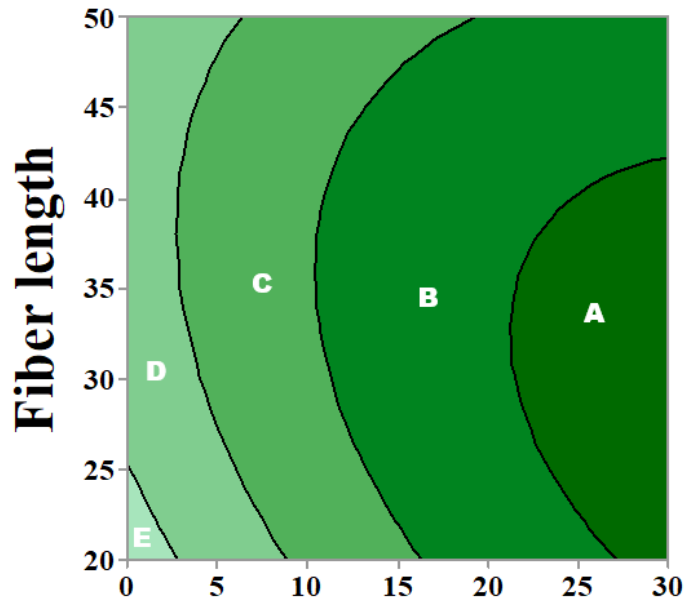

Coir Fiber

(c)

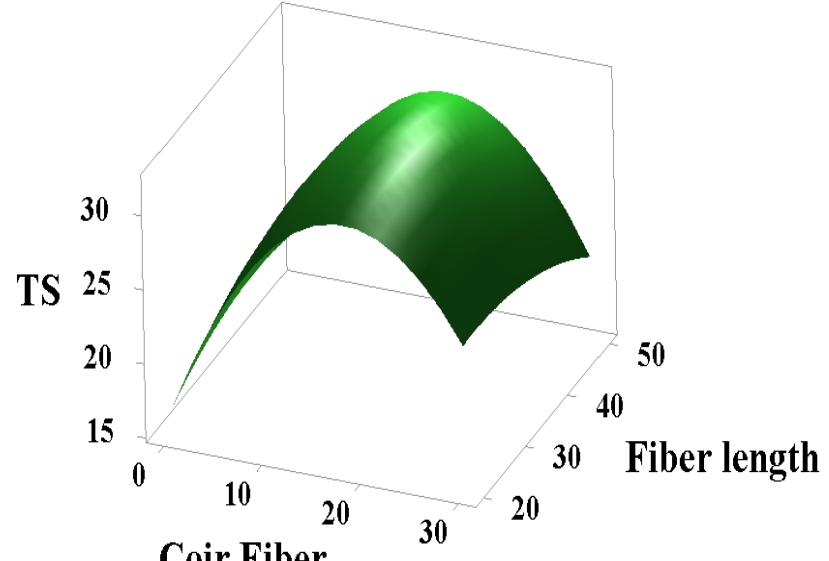

Coir Fiber (b)

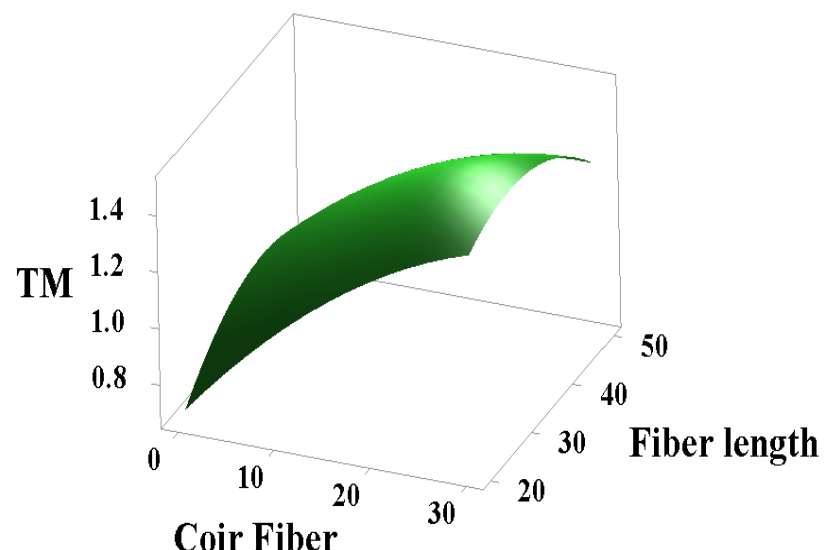

Coir Fiber

(d)

TS and TM represent tensile strength and tensile modulus.

Fig. 4: Variation in tensile strength and modulus with simultaneous combination of fiber proportion and fiber length as represented in (a) 2D contour plot (b) 3D response surface plot for tensile strength and (c) 2D contour plot (d) 3D response surface plot for tensile modulus.

From the plot (Fig 4a), region A indicates area in which TS is greater than $30 \mathrm{MPa}$ (area in which maximum TS value of $35.9 \mathrm{MPa}$ was attained). The implication is that to achieve TS value above $30 \mathrm{MPa}$, coir fiber proportion (treated in $1.7 \mathrm{M} \mathrm{NaOH}$ solution) is between 13 and $22.8 \mathrm{wt}$. \% while fiber length is in the range of 20 to $47 \mathrm{~mm}$. As the plot trended towards region $\mathrm{B}$, the strength reduced (between 28 and $30 \mathrm{MPa}$ ). In attaining $28-30 \mathrm{MPa}$, fiber proportion would be between 9.5 - 13 wt. \% and $22.8-26.5 \%$, while fiber length will be in the range of 20-50 mm. Region $\mathrm{C}$ is the portion where tensile of 26 to $28 \mathrm{MPa}$ can be attained with fiber 
proportion of 7.2 - 9.5 MPa and 26.5 -29.5 MPa while fiber length lies between 20 to $50 \mathrm{~mm}$. Tensile strength of $24-26 \mathrm{MPa}$ lies in region D with fiber loading 5.4-7.2\% and 29.5- 30 $\%$.Region $\mathrm{E}$ with fiber proportion of 3-5.4 coir fiber and length 20-50 mm length will produce composite of 22-24 MPa, while region F requires fiber content of 2.2-3 wt. \% (length 20-30 mm) will produce 20-22 $\mathrm{MPa}$. Also, region $\mathrm{G}$ and $\mathrm{H}$ are portions where strength value of 18-20 MPa at fiber proportion of $0.9-2.2 \mathrm{wt}$ \% (length $20-30 \mathrm{~mm}$ ) is attained.

The 3D response surface plot (3DRSP) (Fig. 4b) is dome shaped affirming the quadratic regression model obtained at varying fiber proportion. This plot shows increasing value for TS as a consequence of increasing fiber wt. fraction and fiber length up to maximum (turning point) after which there was further decline. Optimization response carried out depicts optimum tensile strength of $31.8 \mathrm{MPa}$ with the inclusion of $17 \%$ wt. coir fiber, length $30.9 \mathrm{~mm}$.

\section{e. 2D contour and 3D response surface plot for tensile modulus}

From the plot (Fig. 4c), region A indicates area in which TM is between 1.2-1.4 GPa (area in which maximum TM value of $1.59 \mathrm{MPa}$ was obtained). Implication of this is that to achieve TM value between 1.2-1.4 GPa coir fiber proportion (treated in $1.7 \mathrm{M} \mathrm{NaOH}$ solution) must be between 27 and $30 \mathrm{wt}$. \% while fiber length is in the range of 20 to $42 \mathrm{~mm}$. Consequently, in region $\mathrm{B}$ tensile modulus ranged between 1-1.2 GPa; which is achieved with fiber proportion of 16.8 to 27 wt. \% coir fiber cut to length of range of 20 to $50 \mathrm{~mm}$. Region $\mathrm{C}$ is characterized with modulus value of $0.8-1.0 \mathrm{GPa}$ and this can be realized when fiber proportion of 8.5-16.8 wt. \% was added at fiber length of 20 to $50 \mathrm{~mm}$. Region D also presents region in which less than 0.8 GPa modulus will be recorded. Alkaline treated fiber of length 20 to $50 \mathrm{~mm}$ at weight fraction of $0-8.5 \%$ will achieve that.

The 3D response surface plot (3DRSP) (Fig. 4d) shows uptrend at the combination of fiber proportion and fiber length up to peak. Optimization response carried out depicts optimum tensile modulus of $1.49 \mathrm{GPa}$ with the inclusion of $30 \%$ wt. coir fiber, length $29.7 \mathrm{~mm}$. 


\subsection{Flexural strength (FS) and flexural modulus (FM)}

\section{a. Analysis of experimental results}

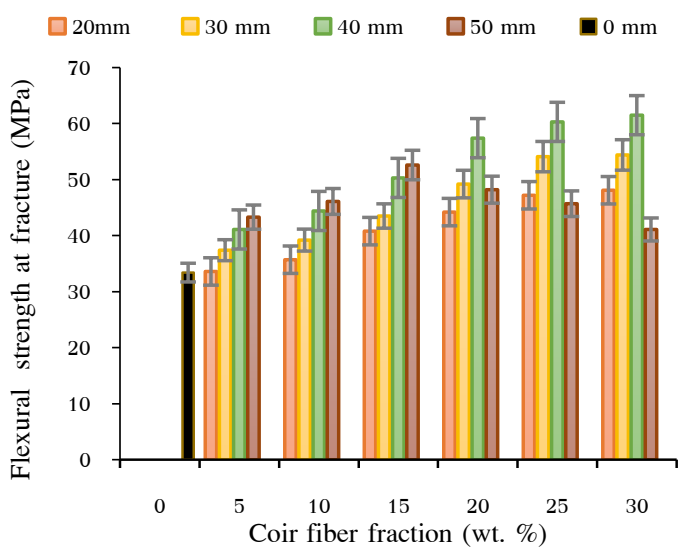

(a)

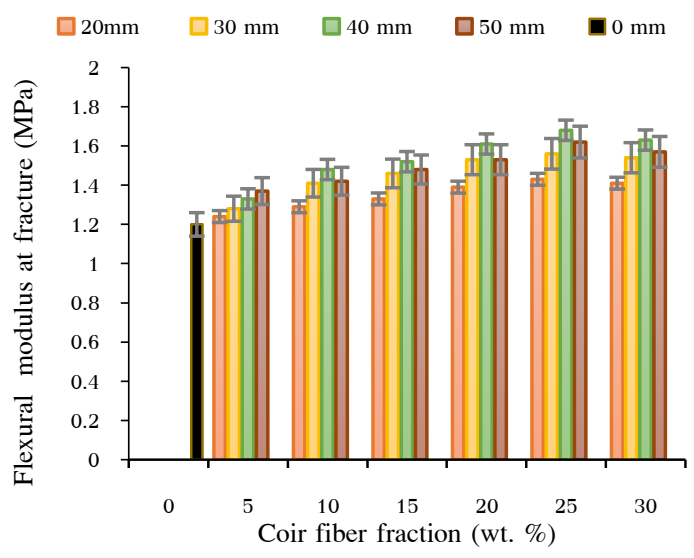

(b)

Fig. 5(a): Influence of coir weight fraction $(0,5,10,15,20,25$ and 30 wt. \%) and fiber length $(20,30,40,50$ and $60 \mathrm{~mm})$ on (a) flexural strength (b) flexural modulus.

Flexural strength (FS) of treated coir fiber reinforced polypropylene composite is depicted in Fig. 5a. FS peaked at $30 \mathrm{wt}$. \% coir fiber addition (cut to $40 \mathrm{~mm}$ ) which is in tandem with the study of $[46,51]$. Maximum value attained in this study for FS is $61.5 \mathrm{MPa}$ which gave an increase of $95.9 \%$ relative to $31.4 \mathrm{MPa}$ recorded at $0 \mathrm{wt}$. \% fiber.

While considering fiber length, it was observed that flexural strength improved with increasing fiber length from $20-40 \mathrm{~mm}$. The increase can be linked to fiber network formed and improved adhesion as a result of alkaline treatment of the fiber. Addition of $50 \mathrm{~mm}$ fiber length presented appreciation in FS from 5 to $15 \mathrm{wt}$ \% coir while depreciation was noted from 20 to $30 \mathrm{wt}$ \% coir addition and this can be traced to fiber clog and interlocking which reduced resistance to bending. [53] reported higher value of FS with increment in fiber length from 10 to $30 \mathrm{~mm}$. This validates the discovery made in this study as per variation in fiber length. Studies of [54] exposed rise in flexural strength of developed polypropylene composite reinforced with Banana/glass fiber from 0 to $30 \%$ of the fiber, a scene also reported in this study. The study of [55] also affirm rise in flexural strength of up to $40 \%$ on addition of kenaf fiber to polypropylene matrix. This observation validates observations made in this research in that incorporation of agro waste fibers enhances flexural strength.

Flexural rigidity (modulus) varies increasingly with fiber loading up to $25 \%$ before slight reduction in value on incorporation of $30 \mathrm{wt}$. \% coir fiber. With fiber length from $20 \mathrm{~mm}$ to 50 $\mathrm{mm}$ rigidity improved on the dint of even stress distribution and transfer within matrix based on fiber presence. Alkaline treatment of the fiber contributed to the feat. The uptrend in FM with fiber loading corroborates the study of [50] [56] [57] [51]. At increasing fiber content, lower 
flexural strain was reported indicating enhanced rigidity at higher weight fraction of fiber. [50] linked this to entanglement between polymer chain and fiber.

\section{b. Regression model of flexural strength of coir-polypropylene of varying length}

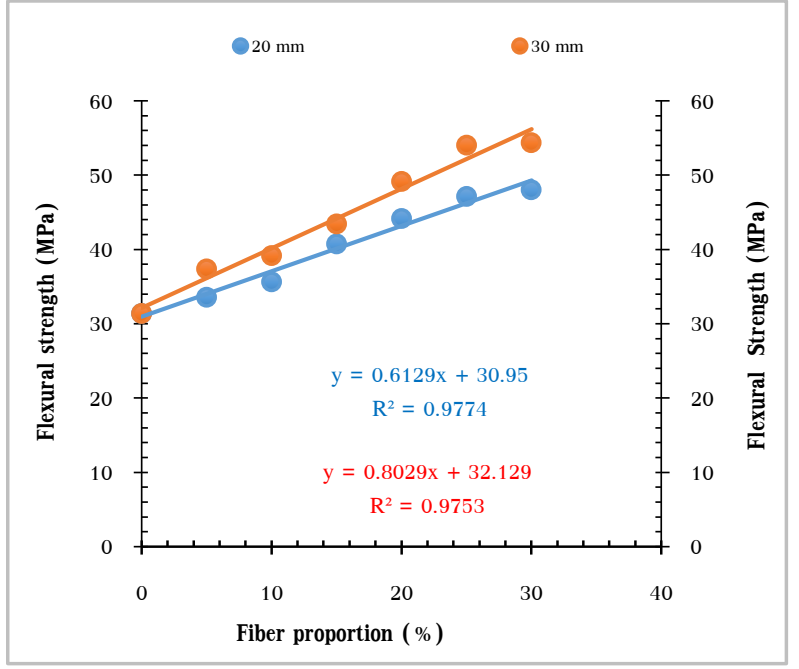

(a)

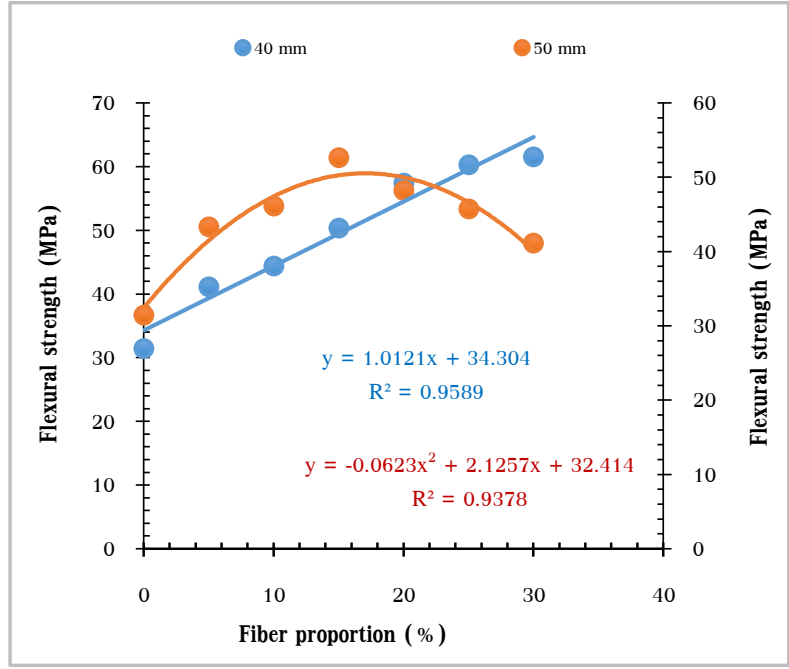

(b)

Fig. 6: Regression model for flexural strength at varied coir fiber proportion and lengths of (a) 20 $30 \mathrm{~mm}$ (b) 40 and $50 \mathrm{~mm}$.

The regression model as represented in Fig 6 a and b is linear reflecting a linear relationship between flexural strength (FS) and coir fiber weight percent at $20 \mathrm{~mm}$ to $40 \mathrm{~mm}$ length. Best line of fit at $50 \mathrm{~mm}$ length presented a quadratic regression model in which TS value rose to a peak before decline. Coefficients of determination $\mathrm{R}^{2}$ are $0.9774,0.9753,0.9589$ and 0.9378 for fiber length 20,30, 40 and $50 \mathrm{~mm}$ length respectively. From the value of the $\mathrm{R}^{2}$, deduction made is that as fiber length increased from 20 to $40 \mathrm{~mm}$, there is lower correlation between FS and fiber loading. 


\section{c. Regression model of flexural modulus of coir-polypropylene of varying length}
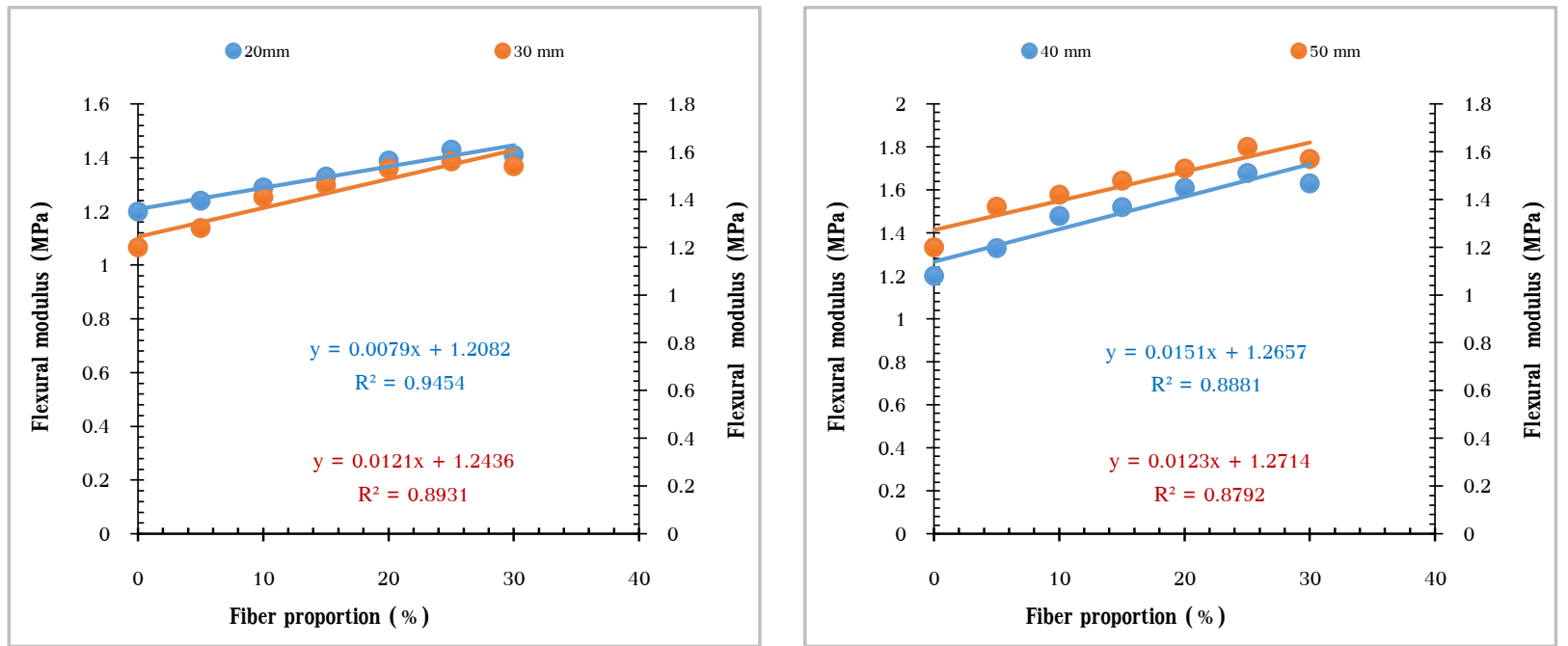

Fig. 7: Regression model for flexural modulus (FM) at varied coir fiber proportion and lengths of (a) 20 and $30 \mathrm{~mm}$ (b) 40 and $50 \mathrm{~mm}$.

The regression model as represented in Fig $7 \mathrm{a}$ and $\mathrm{b}$ is linear reflecting a linear relationship between flexural modulus (FM) and coir fiber weight percent at $20 \mathrm{~mm}$ to $50 \mathrm{~mm}$ length. Coefficients of determination $\mathrm{R}^{2}$ are $0.9454,0.8931,0.8881$ and 0.8792 for fiber length 20,30 , 40 and $50 \mathrm{~mm}$ length respectively. From the value of the $\mathrm{R}^{2}$, correlation between the data values and flexural modulus response reduced with curing length, though increased with fiber loading.

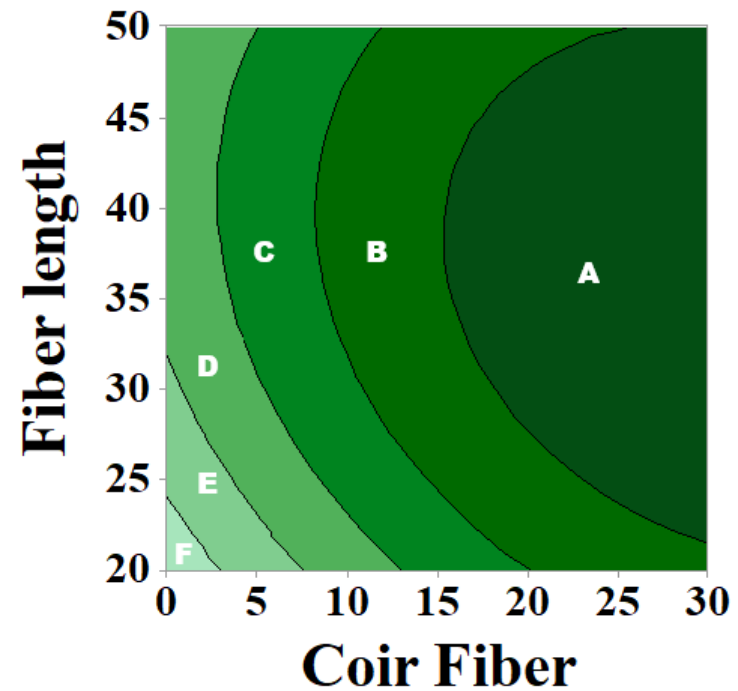

(a)

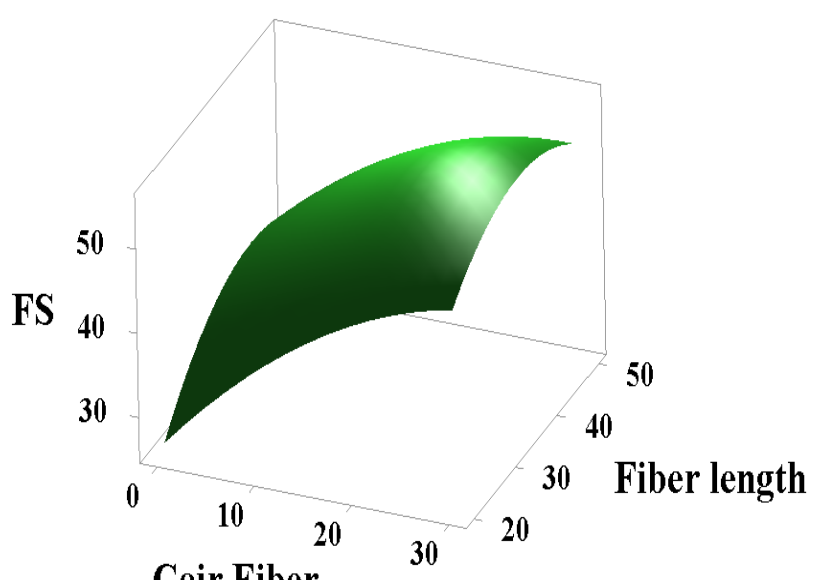

Coir Fiber

(b) 


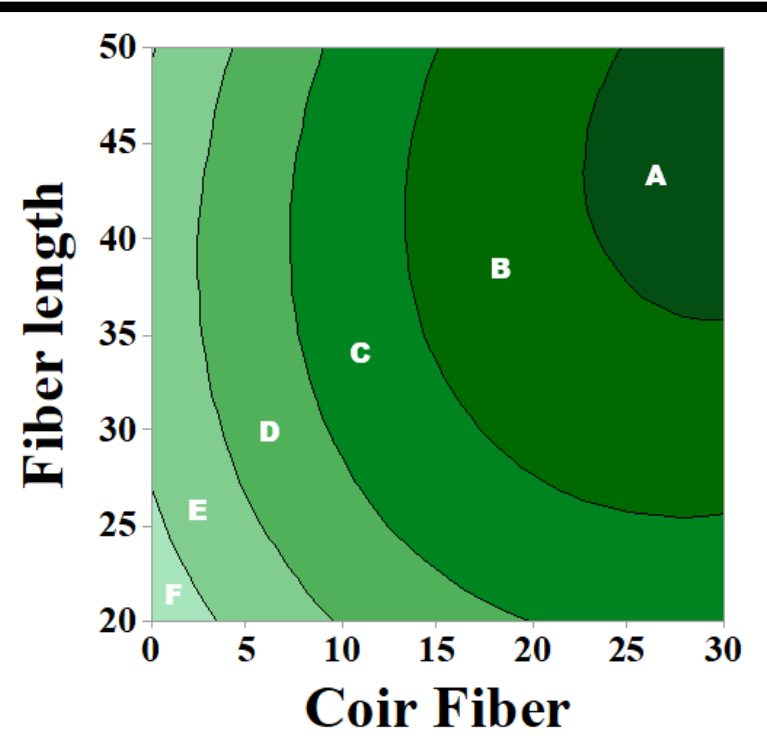

(c)

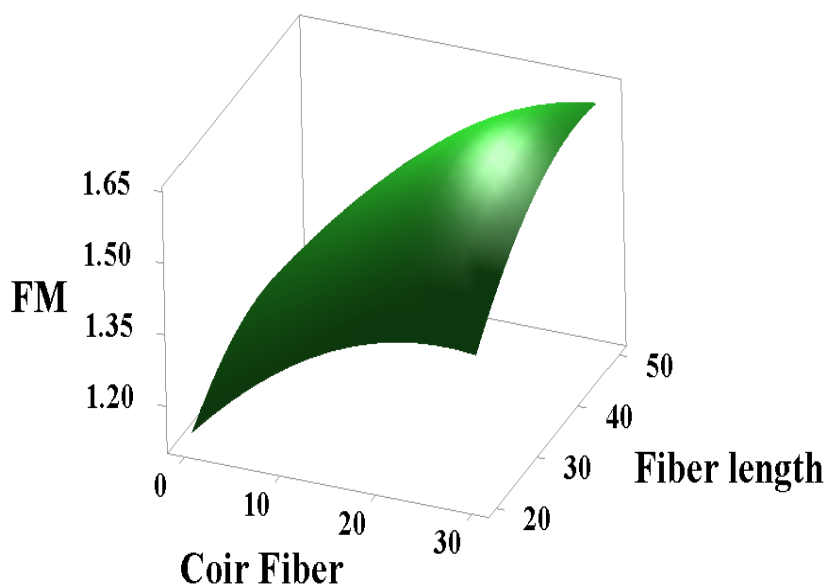

(d)

Fig. 8: Variation in flexural strength and modulus with simultaneous combination of fiber proportion and fiber length as represented in (a) 2D contour plot (b) 3D response surface plot for tensile strength and (c) 2D contour plot (d) 3D response surface plot for tensile modulus.

\section{d. 2D contour and 3D response surface plot for flexural strength}

From the 2D contour plot (Fig 8a), region A indicates area in which FS is above $50 \mathrm{MPa}$ (area in which maximum FS value of $61.5 \mathrm{MPa}$ was obtained). Therefore, in attaining FS value above 50 $\mathrm{MPa}$, coir fiber proportion (treated in $1.7 \mathrm{M} \mathrm{NaOH}$ solution) should be between 15.5 and 30 wt. $\%$ while fiber length is in the range of 21.8 to $50 \mathrm{~mm}$. Region B flexural strength ranged between 45 and $50 \mathrm{MPa}$; which is achieved with fiber proportion of 9.5 to $15.5 \mathrm{wt}$. \% coir fiber cut to length of range of 20 to $50 \mathrm{~mm}$. Region $\mathrm{C}$ is characterized with flexural strength of 40-45 $\mathrm{MPa}$ and this can be realized when fiber proportion of 4.8-9.5 wt. \% fiber is added at length of 20 to $50 \mathrm{~mm}$. Region D (flexural strength 35 to $40 \mathrm{MPa}$ ) presents region in which 35 to $40 \mathrm{MPa}$ flexural strength will be realized with incorporation of coir cut to 20 to $50 \mathrm{~mm}$ length in weight fraction of 0-4.8\%. In the case of region E alkaline treated fiber of length 20 to $36 \mathrm{~mm}$ and 45.7 to $50 \mathrm{~mm}$ at weight fraction of $0-5.8 \%$ will give $\mathrm{FS}$ value of 30 to $35 \mathrm{MPa}$. Finally, region $\mathrm{F}$ shows that attainment of 25 to $30 \mathrm{MPa}$ flexural strength of treated coir-polypropylene composite requires fiber proportion of $0-4.2 \mathrm{wt}$. \% at fiber length of 20 to $25.7 \mathrm{~mm}$.

The 3D response surface plot (3DRSP) (Fig. 8b) shows uptrend at the combination of fiber proportion and fiber length up to peak. Optimization response carried out depicts optimum tensile modulus of $54 \mathrm{MPa}$ with the inclusion of $29.7 \%$ wt. coir fiber, length $36.05 \mathrm{~mm}$.

\section{e. 2D contour and 3D response surface plot for flexural modulus}

From the 2D contour plot (Fig 8c), region A indicates area in which FM is above 1.6 GPa (area in which maximum FS value of $1.68 \mathrm{GPa}$ was obtained). Therefore, in attaining FM value above $1.68 \mathrm{GPa}$, alkaline coir fiber proportion should be between 23.5 and $30 \mathrm{wt}$ \% while fiber length is in the range of 32 to $50 \mathrm{~mm}$. Region B FM ranged between 1.5 and $1.6 \mathrm{GPa}$; which is achieved with fiber proportion of 14.2 to $23.5 \mathrm{wt}$. \% coir fiber cut to length of range of 26.8 to $50 \mathrm{~mm}$. 
Region $\mathrm{C}$ is characterized with flexural modulus of 1.4-1.5 GPa and this can be realized when fiber proportion of 19.2-30 wt. \% fiber is added at length of 20 to $50 \mathrm{~mm}$. In region D, FM of 1.3to $1.4 \mathrm{GPa}$ will be attained with incorporation of coir cut to 20 to $50 \mathrm{~mm}$ length in weight fraction of 9.7-19.2\%. Region $\mathrm{E}$ is the area in which $1.2-1.3 \mathrm{GPa}$ flexural modulus can be attained and in achieving this, coir fiber of length 20 to 50 must be incorporated into polypropylene matrix in weight fraction of $3.7-9.7 \%$. F shows region in which flexural modulus will be less than $1.2 \mathrm{GPa}$ when $0-3.7 \mathrm{wt}$. $\%$ fiber cut to 0 to $26.5 \mathrm{~mm}$ is added.

The 3D response surface plot (3DRSP) shows uptrend at the combination of fiber proportion and fiber length up to peak. Optimization response carried out depicts optimum tensile modulus of $1.63 \mathrm{GPa}$ with the inclusion of $30 \%$ wt. coir fiber, length $45.15 \mathrm{~mm}$.

\subsection{Impact strength (IS) and Hardness (HD)}

\section{a. Analysis of experimental results}

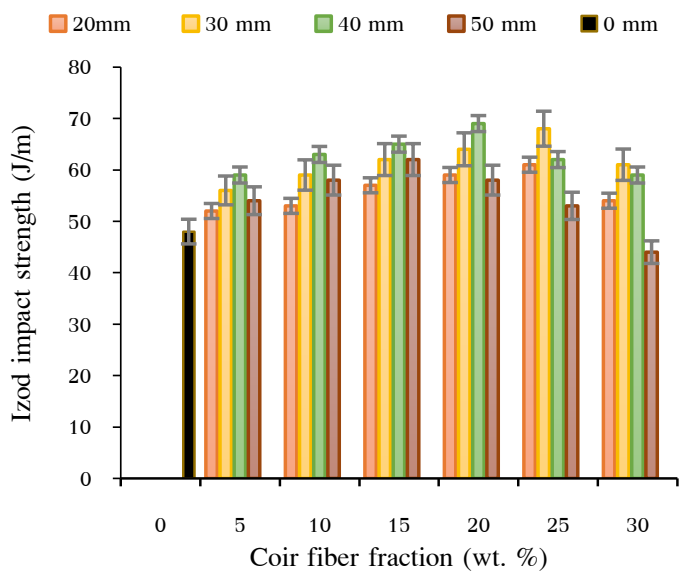

(a)

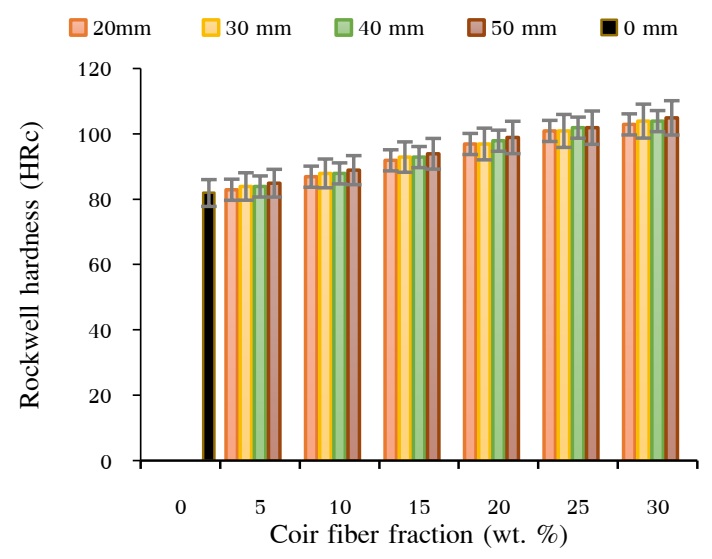

(b)

Fig. 9: Influence of coir weight fraction $(0,5,10,15,20,25$ and 30 wt. \%) and fiber length (20, $30,40,50$ and $60 \mathrm{~mm}$ ) on (a) impact strength (b) hardness.

\section{Impact strength}

Fig. 9 presents variation of Izod impact strength at different weight fraction of coir fiber at different length between 20 to $50 \mathrm{~mm}$. There was rise in impact strength from $0 \mathrm{wt}$. \% to $25 \mathrm{wt}$. $\%$ of the fiber cut to $20-30 \mathrm{~mm}$. This feat ensued on account of strong interfacial linkage formed and the ability to absorb energy [48].Integration of $30 \mathrm{wt} . \%$ fraction of fiber resulted in lower impact strength. According to [58], with increasing fiber content, there is increased tendency of fiber agglomeration which serves as region of stress concentration impacting brittleness in the material. Similar to the occurrence when 20 to $30 \mathrm{~mm}$ fiber was added, effect of $40 \mathrm{~mm}$ coir fiber length improved impact strength but up to $15 \mathrm{wt}$. \%. Lowering of impact strength at 20 to $30 \mathrm{wt}$. \% of fiber cut to $40 \mathrm{~mm}$ length can be associated with agglomeration of fiber and entanglement. Maximum impact strength was realized when 25 wt. \% fiber of length $30 \mathrm{~mm}$ and when $20 \mathrm{wt}$. \% of length $40 \mathrm{~mm}$ were integrated into the polymer matrix. Utilization 
of bamboo fiber in polypropylene in [59] was observed to give increasing value for impact strength up to $60 \mathrm{wt}$. \% of the fiber. Same experience was noted in [60] in which IS increased up to $30 \mathrm{wt}$. \% of coir affirming result of this study. Also, in [61], utilization of bamboo fiber as reinforcement in polypropylene led to appreciation in impact strength with fiber loading from 17 to $58 \%$ bamboo fiber just as highlighted in this study.

Hardness value of polypropylene reinforced with coir fiber at fiber loading 0 to $30 \mathrm{wt}$ \% cut to 20 to $50 \mathrm{~mm}$ length pinpoint appreciable increase in hardness with respect to fiber loading. Meanwhile, with respect with fiber length, there was no appreciable increase implying fiber length contributes little to hardness of the composite developed. Hardness increase with respect to fiber loading is linked to increase stiffness exhibited in the composites [60]. It is also traced to enhanced interfacial adhesion within the matrix. Maximum hardness is attained when $30 \%$ weight fraction of the fiber (length of $50 \mathrm{~mm}$ ) was utilized in reinforcing the polymer. At that point, enhanced hardness may ensue based on complex fiber network created within the matrix resulting in enhanced resistance to indentation.

\section{b. Regression model of impact strength of coir-polypropylene of varying length}

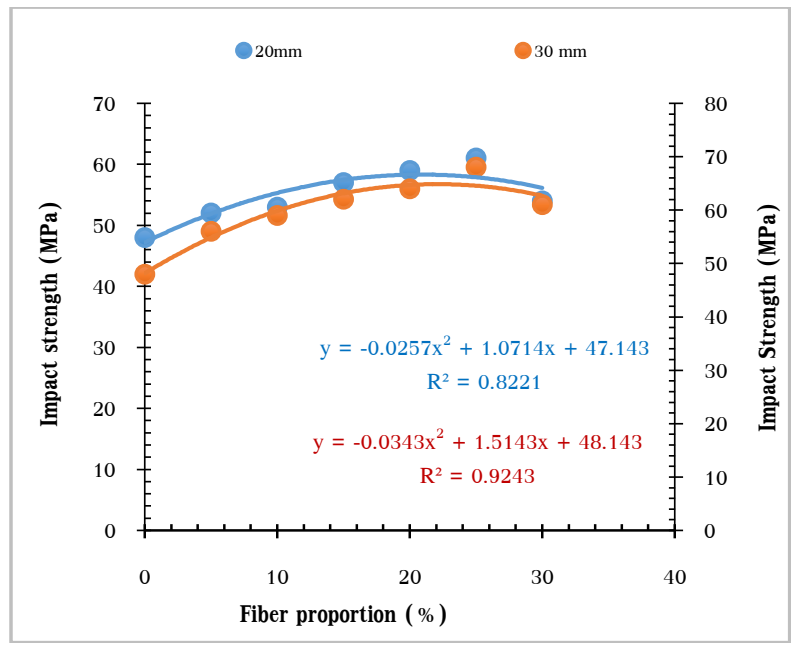

(a)

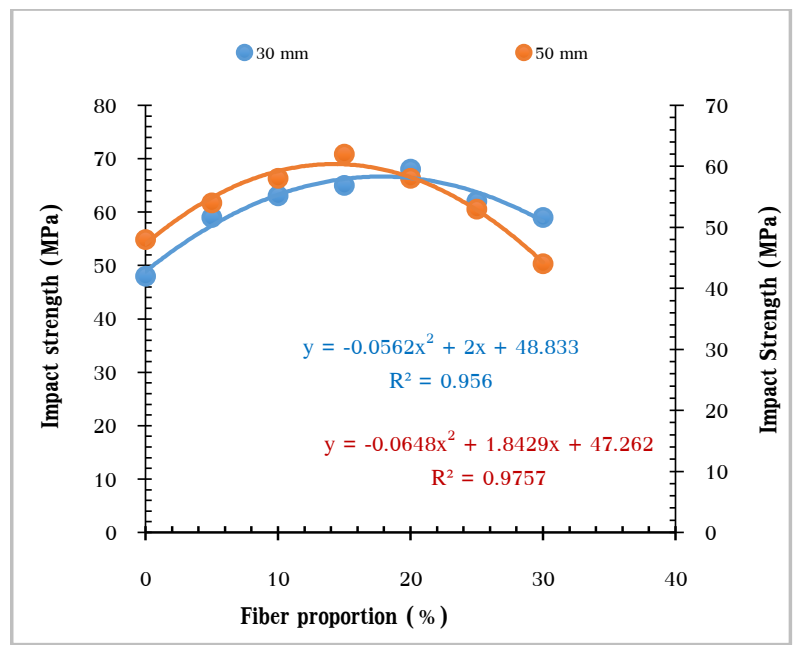

(b)

Fig. 10: Regression model for impact strength (FM) at varied coir fiber proportion and lengths of (a) 20 and $30 \mathrm{~mm}$ (c) 40 and $50 \mathrm{~mm}$.

The regression model of the best line of fit are as represented in Fig $10 \mathrm{a}$ and $\mathrm{b}$. The models are quadratic with coefficient of determination $\left(\mathrm{R}^{2}\right)$ being $0.8221,0.9243,0.956$ and 0.9757 for coir fiber weight percent at $20 \mathrm{~mm}$ to $50 \mathrm{~mm}$ length. From the value of the $\mathrm{R}^{2}$, correlation between the impact strength response and fiber weight proportion increased with fiber length. 


\section{c. Regression model of hardness of coir-polypropylene of varying length of coir}

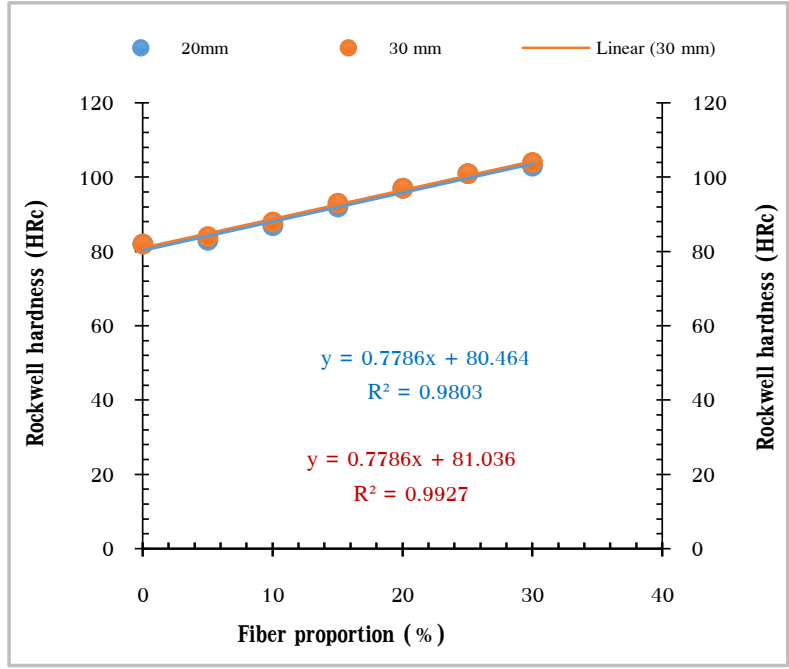

(a)

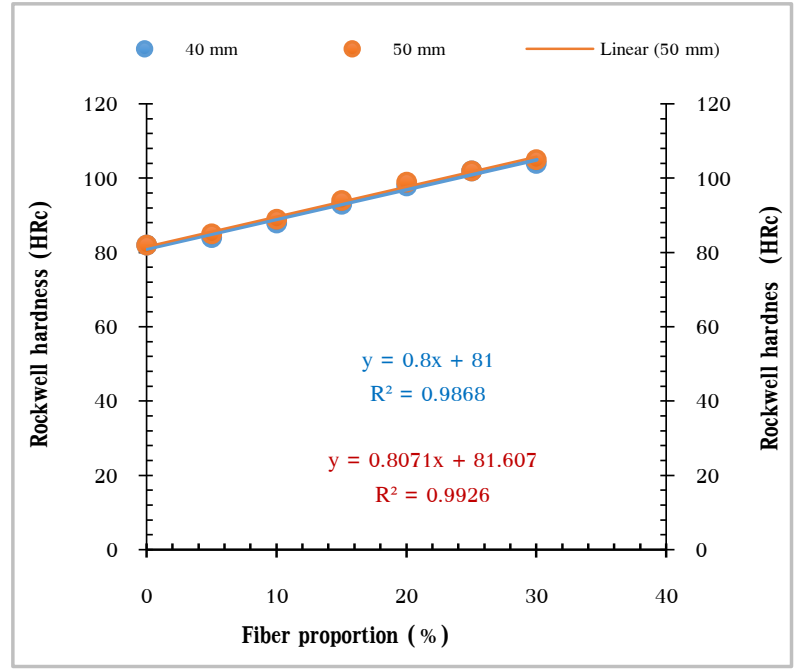

(b)

Fig. 11: Regression model for hardness (HD) at varied coir fiber proportion and lengths of (a) 20 and $30 \mathrm{~mm}$ (c) 40 and $50 \mathrm{~mm}$.

The regression model as represented in Fig $11 \mathrm{a}$ and $\mathrm{b}$ is linear reflecting a linear relationship between hardness (HD) and coir fiber weight percent at $20 \mathrm{~mm}$ to $50 \mathrm{~mm}$ length. Coefficients of determination $\mathrm{R}^{2}$ are 0.9803, 0.9927, 0.9868 and 0.9926 for fiber length 20,30, 40 and $50 \mathrm{~mm}$ length respectively. From the value of the $\mathrm{R}^{2}$, there is very high level of correlation between the data fiber input and hardness response.

\section{d. 2D contour and 3D response surface plot}

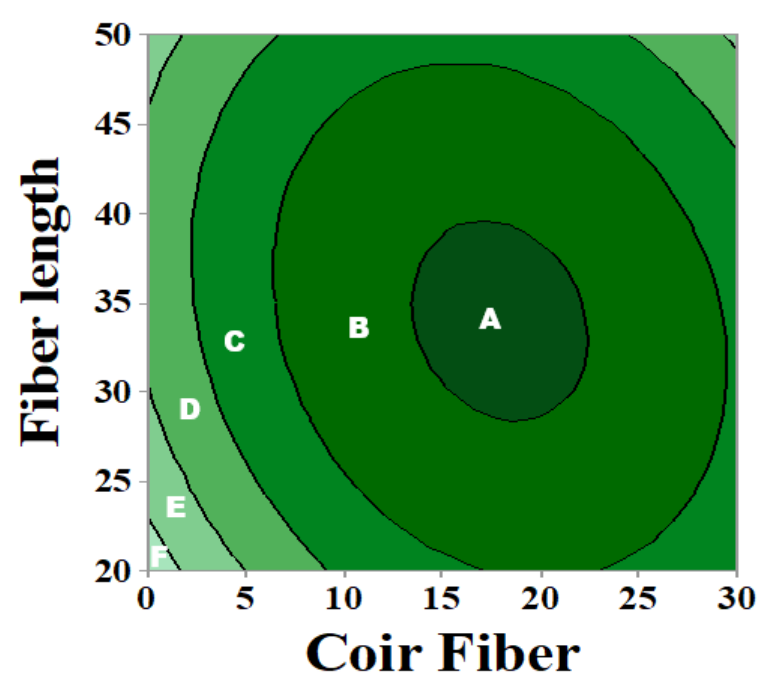

(a)

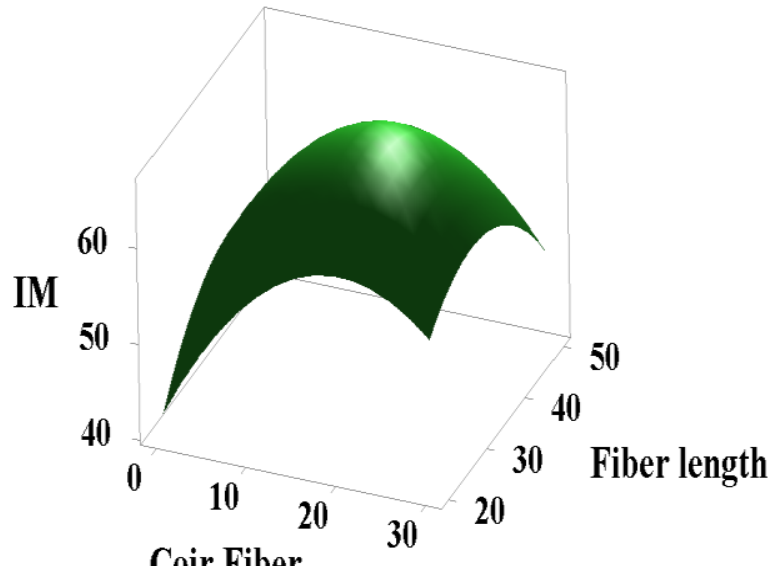

Coir Fiber

(b) 


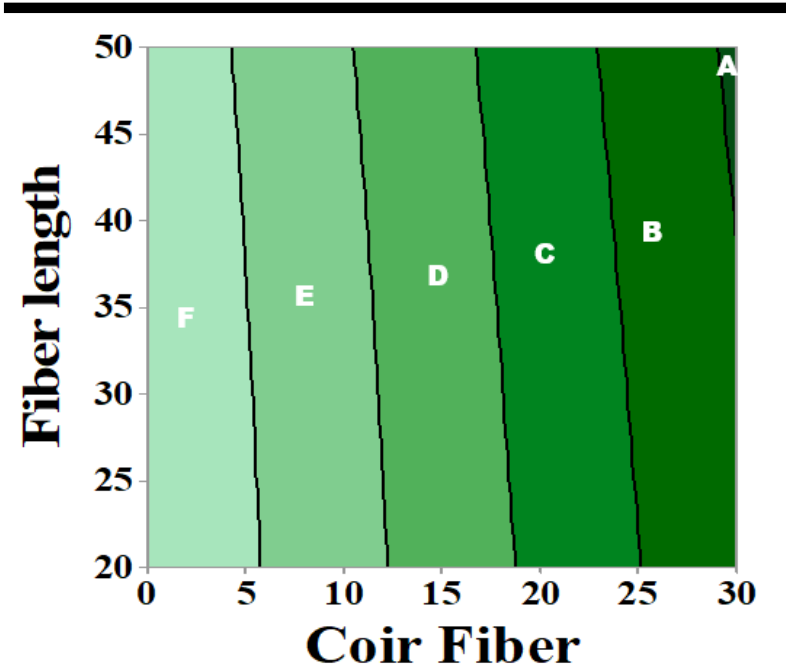

(c)

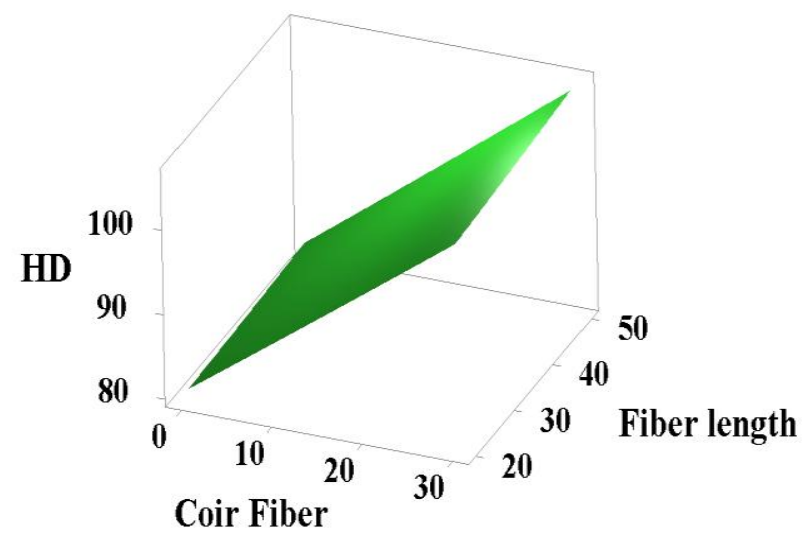

(d)

Fig. 12: Variation in impact strength (IM) and hardness (HD) with simultaneous combination of fiber proportion and fiber length as represented in (a) 2D contour plot (b) 3D response surface plot for tensile strength and (c) 2D contour plot (d) 3D response surface plot for tensile modulus.

\section{d. 2D contour and 3D response surface plot for impact strength}

From the 2D contour plot (Fig 12a), region A indicates area in which IM is above $65 \mathrm{~J} / \mathrm{m}$ (area in which maximum FS value of $68 \mathrm{~J} / \mathrm{m}$ was obtained). Therefore, in attaining IS value above 65 $\mathrm{J} / \mathrm{m}$, coir fiber proportion (treated in $1.7 \mathrm{M} \mathrm{NaOH}$ solution) should be between 14.5 and $22.5 \mathrm{wt}$. $\%$ while fiber length is in the range of 27.5 to $38 \mathrm{~mm}$. Region B IS ranged between 60 and 65 $\mathrm{J} / \mathrm{m}$; which is achieved with fiber proportion of 5.75 to $29.7 \mathrm{wt}$. \% coir fiber cut to length of range of 20 to $47.5 \mathrm{~mm}$. Region $\mathrm{C}$ is characterized with impact strength of $55-60 \mathrm{~J} / \mathrm{m}$ and this can be attained when fiber proportion of 9.2-30 wt. \% fiber is added at length of 20 to $50 \mathrm{~mm}$. Region D presents region in which 50 to $55 \mathrm{MPa}$ flexural strength will be realized with incorporation of coir cut to 20 to $50 \mathrm{~mm}$ length in weight fraction of 5-9.2\% and $30 \mathrm{wt}$. \%. In the case of region E alkaline treated fiber of length 20 to $30.3 \mathrm{~mm}$ at weight fraction of $2.2-5.8$ $\%$ will give FS value of 45 to $50 \mathrm{~J} / \mathrm{m}$. Finally, region $\mathrm{F}$ shows that attainment of less than $45 \mathrm{~J} / \mathrm{m}$ impact strength of treated coir-polypropylene composite requires fiber proportion of $0-2.2 \mathrm{wt}$ \% at fiber length of 20 to $22.5 \mathrm{~mm}$.

The 3D response surface plot (3DRSP) (Fig 12b) is dome shaped affirming the quadratic regression model obtained at varying fiber proportion. This plot shows increasing value for IS as a consequence of increasing fiber wt. fraction and fiber length up to maximum (turning point) after which there was further decline. Optimization response carried out depicts optimum tensile modulus of $65.77 \mathrm{~J} / \mathrm{m}$ with the inclusion of $17.88 \mathrm{wt}$. coir fiber, length $44.94 \mathrm{~mm}$.

\section{e. 2D contour and 3D response surface plot for hardness}

From the 2D contour plot (Fig 12c), region $\mathrm{A}$ is the portion in which hardness records value above $105 \mathrm{HRc}$ and fiber proportion is between 28 to $30 \mathrm{wt} . \%$ at fiber length of 37.2 to $50 \mathrm{~mm}$. Second region from the left (region B) is characterized with hardness value between 100 and 105 
HRc and attained between fiber portion of 23.8 and 30 wt. \%; fiber length between 20 and 50 $\mathrm{mm}$. In region C, hardness value of 95 to $100 \mathrm{HRc}$ can be achieved at fiber fraction between 17.8 and $23.8 \%$; length of 20 to $50 \mathrm{~mm}$. The $4^{\text {th }}$ portion (region D), with fiber loading of 11.4 and 12.8; length 20 to $50 \mathrm{~mm}$, hardness value of 90 to $95 \mathrm{HRc}$ can be realized. To achieve HD of 85 to $90 \mathrm{HRc}$, fiber loading of 4.2 to $11.4 \mathrm{wt}$. \%; length of 20 to $50 \mathrm{~mm}$ is adequate. Finally, for hardness less than $85 \mathrm{HRc}$, fiber proportion of 0 to $4.2 \%$; length of 20 to $50 \mathrm{~mm}$ will suffice.

The 3D response surface plot (3DRSP) (Fig. 12d) is trended upward with increasing combination of fiber proportion (0 to $30 \mathrm{wt}$. \%) and fiber length $(20$ to $50 \mathrm{~mm}$ ) affirming the linear regression model obtained at varying fiber proportion. Optimization response carried out depicts optimum tensile modulus of $105.83 \mathrm{HRc}$ with the inclusion of $30 \mathrm{wt}$. coir fiber, length $50 \mathrm{~mm}$.

\section{Optimization}

Minitab 17 was employed in analyzing property values towards realizing optimum mix proportion with respect to fiber content and length. Optimum value was fiber proportion of $25.76 \%$ at fiber length of $34.85 \mathrm{~mm}$ with desirability of 0.7513 . Table 2 indicates optimum value for each property considered.

Table 1: Optimized Values of property of Coir/Coconut shell powder (25.76 wt. \% Coir fiber of length $34.85 \mathrm{~mm}$.

\begin{tabular}{ccc} 
Properties & Value & Desirability \\
\hline Tensile strength & $29.41 \mathrm{MPa}$ & 0.6291 \\
Tensile modulus & $1.4282 \mathrm{GPa}$ & 0.7926 \\
Flexural strength & $53.6916 \mathrm{MPa}$ & 0.7221 \\
Flexural Modulus & $1.5829 \mathrm{GPa}$ & 0.7978 \\
Impact strength & $64.0909 \mathrm{~J} / \mathrm{m}$ & 0.8036 \\
Hardness & $99.9218 \mathrm{HRc}$ & 0.7792 \\
\hline
\end{tabular}

\section{Conclusion}

Influence of coir fiber weight fraction and length on polypropylene matrix was evaluated and optimized. From the result, it was analysed that coir fiber improved enhanced strengths with increasing proportion even as fiber length up to $40 \mathrm{~mm}$ improved the properties. Optimization carried out via surface response employing Minitab version 17 shows that mix proportion of $25.67 \mathrm{wt}$. \% and $34.85 \mathrm{~mm}$ length will give optimum performance of automobile application. 


\section{Reference}

[1] Z. Cerovsky and Mindl, P., 2008. Hybrid Electric Cars, Combustion Engine Driven Cars and their Impact on Environment. Conf. Paper: Power Electronics, Electrical Drives, Automation and Motion SPEEDAM 2008. 10.1109/SPEEDHAM.2008.4581321.

[2] V. Ambrogi, C. Carfagna, P. Cerruti, V. Marturano, 2016. Additives in Polymers. In book: Modification of Polymer Properties (pp. 87 -108). Chapter 4 Publisher: William Andrew Publishing. Editors: Carlos F. Jasso-Gastinel, Jose M. Kenny.

[3] E. Lico, I. Boci, S. Drushku, 2014. Effect of Inorganic additives in Polymeric Fiber Properties. Conf. Paper: Int. Conf. of Textile, Tirana, Albania.

[4] A. Elgozali and F.M. Hassan, 2008. Effect of Additives on the Mechanical Properties of Polyvinyl Chloride. J. sci. Tech. 9(1), 1-12.

[5] D. K. Rajak, D. D. Pagar, P. L. Menezes, E. Linul, 2019. Fiber-Reinforced Polymer Composites: Manufacturing, Properties and Application. Polymers. 11(10), 1667. 10.3390/polym11101667.

[6] L. Mohammed, M. N. M. Ansari, G. Pua, M. Jawaid and M. S. Islam, 2015. A Review on Natural Fiber Reinforced Polymer Composite and Its Application. Int. J. of Polymer Science. Vol. 2015. Article ID 243947. 10.1155/2015/243947.

[7] R. Heamanth, M. Sekar and B. Suresha, 2014. Effects of Fibers and Fillers on Mechanical Properties of Thermoplastic Composites. Indian Journal of Advances in Chemical Science. 2(2014), 28-35.

[8] M. Asim, K. Abdan, M. Jawaid, M. Nasir, Z. Dashtizadeh, M. R. Ishak and M. E. Hoque. A review on Pineapple Leaves Fiber and Its Composite. Int. J. of Polymer Science. Vol. 2015, Article ID 950567, 1-16. 10.1155/2015/950567.

[9] S. M. Sapuan, A. R. Mohamed, J. P. Siregar and M. R. Ishak. Pineapple Leaf Fibers and PALF-Reinfoeced Polymer Composites. In book:Cellulose Fibers: Bio and Nano Polymer Composites, 325-343.

[10] P. Lokesh, T. S. A. Surya Kumari, R. Gopi and G. B. Loganathan, 2019. A Study on Mechanicaln Properties of Bamboo Fiber Reinforced Polymer Composite. Materials today:Proceedings. International Conference on Materials Engineering and Characterization. 10.1016/j.matpr.2019.11.100.

[11] K. Ganesan, C. Kailasanathan, M. R. Sanjay, P. Senthamaraikannan and S. S. Saravanakumar. A New Assessment on Mechanical Properties of Jute fiber Mat With Egg Shell Powder/Nanoclay-Reinforced Polyester matrix Composites. J. of Natural Science. 1-9. 10.1080/15440478.2018.1500340.

[12] N. Kumar, S. Angra and R. S. Walia. Development and Comparison of tensile and Compresive Strength and Percentage Shrinkage of Glass-Jute Hybrid Fiber Reinforced 
Polymer Composites. IOP Conf. Series: Journal of Physics: Conf. Series 1240 (2019) 012123. 10.1088/1742-6596/1240/1/012123.

[13] M. R. Sanjay, P. Madhu, M. Jawaid, P. Senthamaraikannan, 2017. Characterization and Properties of Natural Fiber Polymer Composites: a Comprehensive Review. Journal of Cleaner Production. 172. 10.1016/j.jclepro.2017.10.101.

[14] S. M. Harle, 2014. The Performance of Natural Fiber Reinforced Polymer Composites: A Review. Int. J. of Civil Engineering Research. 5(3), 285-288.

[15] F. Mahir, K. Keya, B. Sarker, K. Nahiun and R. Khan, 2019. A Brief Review on Natural Fiber used As a Replacement of Synthetic Fiber in Polymer Composites. 1, 88-99. 10.25082/MER.2019.02.007.

[16] S. Monteiro, F. P. D. Lopes, A. Ferreira and D. Nascimento, 2009. Natural Fiber Polymer-Matrix Composites: Cheaper, Tougher, and Enviromental Friendly. JOM. 61, 17-22. 10.1007/s11837-009-0004-z.

[17] P. Pecas, H. V. Carvalho, H. Salman and M. Leite, 2018. Natural Fiber Composites and Their Applications: A Review. J. of Composites Science. 2. 66. 10.3390/jcs2040066.

[18] R. Kozlowski and M. Wladyka-Przybylak, 2004. Uses of Natural Fiber reinforced Plastics. Natural Fibers, Plastics and Composites. 249-274. 10.1007/978-1-4419-90501_14.

[19] H. A. Sallal, 2014. Effect of the Addition of Coconut Shell Powder on Properties of Polyurethane Matrix Composite. Al-Nahrain University, College of Engineering Journal. 17(2), 203-210.

[20] M. Supova, G. Simha-Martynkova and K. Cech Barabaszova, 2010. Effect of Nanofillers Dispersion in Polymer Matrices: A Review. Science of Advanced Materials. 3, 1-25. 10.1166/sam.2011.1136.

[21] G. Haslilywaty, A. K. Siti Fatma, R. Roslim, M. Mohibbah and J. Jefri, 2019. Effect of Bio Fillers on Mechanical Properties of Natural Rubber Latex Films. Key Engineering Materials. 797, 249 - 254. 10.4028/www.scientific.net/KEM.797.249.

[22] N. Gupta, B. Brar and E. Woldesenbet, 2001. Effect of Filler Addition on the Compressive and Impact Properties of Glass Fiber Reinforced Epoxy. Bulletin of Materials Science. 24, 219-223. 10.1007/BF02710105.

[23] M. Gashti Parvinzadeh, 2012. Surface Modification of Synthetic Fibers to Improve Performenace. Global Journal of Physical chemistry. 3, 1-10.

[24] A. Landesmann, C. Seruti and E. Batista, 2015. Mechanical Properties of Glass Fiber Reinforced Polymers Members for Structural Applications. Materials Research. 18. 10.1590/1516-1439.044615.

[25] M. A. Hosen, U. J. Alengaram, M. Z. Jumaat, N. H. R. Sulong and K. M. U. Darain, 2017. Glass Fiber Reinforced Polymer (GFRP) Bars for Enhancing the Flexural 
Performance of RC Beams Using Side-NSM Technique. Polymers, 9, 180. 10.3390/polym9050180.

[26] P. Hiremath, M. Shettar, M. C. Shankar and N. Mohan, 2018. Investigation on Effect of Egg Shell Powder on Mechanical Properties of GFRP Composites. Materials Today: Proceedings. 5, 3014-3018. 10.1016/j.matpr.2018.01.101.

[27] I. O. Oladele, B. A. Makinde-Isola, A. A. Adediran, M. O. Oladejo, A. F. Owa and T. M. A. Olayanju, 2020. Mechanical and Wear Behaviour of Pulverized Poultry Eggshell/Sisal Fiber Hybrid Reinforced Epoxy Composites. Material Research Express. 7(4), 045304. $10.1088 / 2053-1591 /$ ab8585.

[28] C. Merlini, V. Soldi and G. Barra, 2011. Influence of Fiber Surface Treatment and Length on Physio-chemical Properties of Short Random Banana Fiber-Reinforced Castor Oil Polyurethane Composites. Polymer Testing-POLYM TEST. 30, 833 -840. 10.1016/j.polymertesting.2011.08.008.

[29] M. K. Gupta and R. K. Srivastava, 2016. Mechanical, Thermal and Water Absorption Properties of Hybrid Sisal/Jute Fiber Reinforced Polymer Composite. India J. Engineering Materials Sciences. 23. 231-238.

[30] K. V. Akash, R. Sreenivasa, N. S. V. Gupta and A. D. S. Kumar, 2016. IOP Conf. Series. Materials Science and Engineering. 149, 012092. 10.1088/1757-899X/149/1/012092.

[31] J. Duan, H. Wu, W. Fu and M. Hao, 2017. Mechanical Properties of Hybrid Sisal/Coir Fibers Reinforced Polylactide Biocomposites. Polymer Composites. U1201242. 10.1002/pc.24489.

[32] T. P. Sathiskhumar, S. Satheeshkumar and N. Jesuarockiam, 2014. Hybrid Fiber Reinforced Polymer Composites-A Review. J. of Reinforced Plastic and Composites. 33. 454-471. 10.1177/0731684413516393.

[33] K. Zhang, F. Wang, W. Liang, Z, Wang, Z. Duan and B. Yang, 2018. Thermal and Mechanical Properties of Bamboo Fiber Reinforced Epoxy Composites. Polymers. 10, 608. 10.3390/polym10060608

[34] S. K. Chattopadhyay, R. K. Khandal, R. Uppaluri, A. K. Ghoshal, 2010. Bamboo Fiber Reinforced Polypropylene Composites and Their Mechanical, Thermal, and Morphological Properties. Journal of Applied Polymer Science, 119, 1619-1626.

[35] S. Bhaskara , R. Devireddy, S. Biswas, 2015. Physical and Mechanical Behavior of Unidirectional Banana/Jute Fiber Reinforced Epoxy Based Hybrid Composites Polymer Composites. 10.1002/pc.23706

[36] C. Obele and E. Ishidi, 2015. Mechanical Properties of Coir Fiber Reinforced Epoxy Resin Composites for Helmet Shell. Industrial Engineering Letters. 5(7), 67-74 
[37] H. P. G. Santafe, F. D. P. Lopes, L. L. D. Costa and S. Monteiro, 2010. Mechanical Properties of Tensile Tested Coir Reinforced Polyester Composite. 15(2), 113-118.

[38] M. N. Islam, M. A. Gafur and Md. S. Hossain, 2018. HDPE-Coir Composite-Fabrication, Process Parameters and Properties. Materials Science: Advanced Composite Materials. 2(3), 1-7. 10.18063/msacm.v0i0.839.

[39] N. Ayrilmis, S. Jarusombuti, V. Fueangvivat, P. Bauchongkol and R. H. White, 2011. Coir Fiber Reinforced Polypropylene Composite Panel for Automotive Interior Application. Fibers and Polymers, 12, 919. 10.1007/s12221-011-0919-1.

[40] ASTM D 3039/D 3039M-17, Standard Test Method for Tensile Properties of Polymer Matrix. ASTM International. West Conshohocken, PA, 2017. 10.1520/D3039_D3039M17

[41] ASTM D 790-17. Standard Test Method for Flexural Properties of Unreinforced and Reinforced Plastics and Electrical Insulating Materials. ASTM International. West Conshohocken, PA, 2017. 10.1520/D0790-17

[42] ASTM D 256-10 (2018). Standard Test Method for Determining the Izod Pendulum Impact Resistance of Plastics. ASTM International. West Conshohocken, PA, 2018. 10.1520/D0256-10R18.

[43] ASTM D 785-08 (2015). Standard Test Method for Rockwell Hardness of Plastics and Electrical Insulating Materials. ASTM International. West Conshohocken, PA, 2015. 10.1520/D0785-08R15.

[44] X. Li, L. G. Tabil and S. Panigrahi, 2007. Chemical Treatments of Natural Fiber for Use in Natural Fiber-Reinforced Composites. A Review. J. of Polymers and the Environment. 15, 25-33. 10.1007/s10924-006-0042-3.

[45] M. M. Haque, M. Hasan, M. S. Islam and M. E. Ali, 2009. Physico-Mechanical Properties of Chemically Treated Palm And Coir Fiber Reinforced Polypropylene Composites. Bioresource Technology. $100 \quad$ (2009) 4903-4906. 10.1016/j.biortech.2009.04.072.

[46] M. Haque, N. Islam, M. Huque, M. Hasan, S. Islam and S. Islam, 2010. Coir Fiber Reinforced Polypropylene Composites: Physical and Mechanical Properties. Advanced Composite Materials 19 (2010) 91-106. 10.1163/092430409X12530067339325.

[47] M. M. Haque and M. N. Islam, 2011. A Study on the Mechanical Properties of Urea Treated Coir Reinforced Polypropylene Composites. Journal of Thermoplastic Composite Materials 26(2) 139-155. 10.1177/0892705711419698.

[48] S. S. Mir, N. Nafsin, M. Hasan, N. Hasan and A. Hassan, 2013. Improvement of PhysicoMechanical Properties of Coir-Polypropylene Biocomposites by Fiber Chemical Treatment. Materials and Design 52 (2013) 251-257. 10.1016/j.matdes.2013.05.062.

[49] L. Szabo, R. Milotskyi, T. Fujie, T. Tsukegi, N. Wada, K. Ninomiya and K. Takahashi, 2019. Short Carbon Fiber Reinforced Polymers: Utilizing Lignin to Engineer Potentially 

Sustainable Resource-Based
Biocomposites.
Front.
Chem.
$7: 757$. 10.3389/fchem.2019.00757.

[50] S. Siddika, F. Mansura, M. Hasan, and A. Hassan, 2014. Effect of Reinforcement and Chemical Treatment of Fiber on the Properties of Jute-Coir Fiber Reinforced Hybrid Polypropylene Composites. Fibers and Polymers. 15(5), 1023-1028. 10.1007/s12221014-1023-0.

[51] Md. N. Islam, Md. R. Rahman, Md. M. Haque, Md. M. Huque, 2010. PhysicoMechanical Properties of Chemically Treated Coir Reinforced Polypropylene Composites. Composites: Part A 41 (2010) 192-198. 10.1016/j.compositesa.2009.10.006.

[52] S. M. Samia, S. M. N. Hasan, Md. J. Hossain, and M. Hasan, 2012. Chemical Modification Effect on the Mechanical Properties of Coir Fiber. Engineering Journal. 16 (2), 74-83. 10.4186/ej.2012.16.2.73.

[53] T. Hitoshi and Y. Ichihara, 2004. Effect of Fiber length on Mechanical Properties of "Green" Composites Using a Starch-Based Resin and Short Bamboo Fibers. JSME International Journal. Series A, 47(4). 10.1299/jsmea.47.551.

[54] K. S. Sushanta, S. Mohanty, and S. K. Nayak. 2009. Banana/Glass Fiber-Reinforced Polypropylene Hybrid Composites: Fabrication and Performance Evaluation. PolymerPlastics Technology and Engineering, 48: 397-414,

[55] M. Nematollahi, M. Karevan, P. Mosaddegh and M. Farzin, 2019. Morphology, Thermal and Mechanical Properties of Extruded Injection Molded Kenaf Fiber Reinforced Polypropylene Composites. Mater. Res. Express 6 (2019) 095409. 10.1088/2053$1591 / \mathrm{ab} 2 \mathrm{fbd}$.

[56] S. S. Mir, M. Hasan, S. M.N. Hasan, Md. J. Hossain and N. Nafsin, 2015. Effect of Chemical Treatment on the Properties of Coir Fiber Reinforced Polypropylene and Polyethylene Composites. Polymer Composites. 10.1002/pc.23690.

[57] S. K. Saw, G. Sarkhel and A. Choudhury, 2012. Preparation and Characterization of Chemically Modified Jute-Coir Hybrid Fiber Reinforced Epoxy Novolac Composites. Journal of Applied Polymer Science. 125, 3038-3049. 10.1002/app.36610.

[58] A. Karmakar, S. S. Chauhan, J. M. Modak and M. Chanda, 2007. Mechanical Properties of Wood Fiber Reinforced Polypropylene Composite. Composite Part A. 38, 227-233.

[59] X. Chen, Q. Guo and Y. Mi, 1997. Bamboo Fiber-Reinforced Polypropylene Composites: A Study of the Mechanical Properties.Journal of Applied Polymer Science. 69, 18911899. 
International Journal of Advanced Academic Research (Sciences, Technology and Engineering)| ISSN: 2488-9849

Journal DOI: 10.46654/ij.24889849

Vol. 6, Issue 10 (October, 2020) | www.ijaar.org

Article DOI: 10.46654/ij.24889849.e6102

[60] Md. M. Haque, Md. E. Ali, M. Hasan, Md. N. Islam, and H. Kim, 2012. Chemical Treatment of Coir Fiber Reinforced Polypropylene Composites. Ind. Eng. Chem. Res. 2012, 51, 3958-3965. 10.1021/ie200693v.

[61] D. Liu, J. Song, D. P. Anderson, P. R. Chang and Y. Hua, 2012. Bamboo Fiber and Its Reinforced Composites: Structure and Properties. Cellulose. 19, 1449-1480. 10.1007/s10570-012-9741-1. 